\title{
A study of the relationship between time, strength, deformation and fracture of plain concrete*
}

\author{
R. K. Dhir and C. M. Sangha \\ Contribution by C. T. Tam \\ University of Malaya, Pantai Valley, Kuala Lumpur, Malaysia
}

I was interested to read the paper by Dr Dhir and Dr Sangha. However, I would like to comment on their observation that strength is increased after the specimen has been subjected to sustained loading. Their loaded specimens, like those of Coutinho (reference 31 of the paper) were kept in a drying atmosphere. Those of Hughes and Ash (reference 30 of the paper) were sealed (immediately after demoulding) and would have decreasing internal moisture content due to self-desiccation while under load. The common factor appears to be continued loss of moisture while the specimens were under sustained load. In fact, Coutinho found a definite decrease in evaporable water content for specimens subjected to sustained loading.

There have not, to my knowledge, been any published results for specimens kept continuously under water during the creep test except for a recent series of tests I carried out at Calgary ${ }^{(1)}$. Since these were not aimed at the specific point under discussion, the results (Table I) may not be conclusive but they should be of interest. The specimens were $76 \mathrm{~mm}$ diameter by $235 \mathrm{~mm}$ cylinders and the concrete mix contained $9 \cdot 5$ $\mathrm{mm}$ maximum size gravel aggregate and river sand. They were cured for 28 days in a fog-room before loading. A water-jacket surrounded the specimens while they were under sustained loading for 91 days and during a recovery period of 63 days. The sustained load was about 0.25 times the 28 day strength. Unloaded specimens were cured continuously in the fogroom. At the age of 182 days, both types of specimen were tested under short-term loading to failure. The results, as shown in Table $I$, indicated a very slight decrease in strength for 15 out of 18 mixes. The average decrease was about $2 \%$.

The mechanism of strength gain under sustained loading has been attributed to (a) consolidation of concrete, (b) stabilization of micro-cracks and (c), according to Coutinho, forced hydration. The effect

*Pages 197 to 208 of Magazine No. 81. of the last two mechanisms should be even more pronounced for specimens tested in a saturated environment, yet the opposite was observed. An explanation may lie in the fact that, in the drying condition, the water in the diffusible load-bearing layer, as defined by Bazant $^{(2)}$, is more severely reduced. This promotes the formation of new bonds, resulting in a permanent reduction in the area of the diffusible load-bearing layer which has been described by Mills ${ }^{(3)}$ as collapse of structure. The other difference between the tests is that Dr Dhir and Dr Sangha's loaded specimens were monotonically loaded to failure, whereas in the case of my own a period of unloaded recovery was introduced. Re-entry of water to the diffusible load-

TABLE I: Effect of sustained load upon strength.

\begin{tabular}{|c|c|c|c|c|}
\hline \multirow{3}{*}{$\begin{array}{l}\text { Mix } \\
\text { No. }\end{array}$} & \multicolumn{3}{|c|}{$\begin{array}{l}\text { Compressive strength } \\
\qquad\left(\mathrm{N} / \mathrm{mm}^{2}\right)\end{array}$} & \multirow{3}{*}{$\begin{array}{c}\text { Creep } \\
\text { Unloaded }\end{array}$} \\
\hline & \multirow{2}{*}{$\begin{array}{l}\text { At } \\
28 \text { days }\end{array}$} & \multicolumn{2}{|c|}{ At 182 days } & \\
\hline & & $\begin{array}{l}\text { Unloaded } \\
\text { specimens }\end{array}$ & $\begin{array}{c}\text { Creep } \\
\text { specimens }\end{array}$ & \\
\hline 1 & $77 \cdot 4$ & $84 \cdot 2$ & $83 \cdot 7$ & 0.994 \\
\hline 2 & $89 \cdot 3$ & $94 \cdot 3$ & $93 \cdot 1$ & 0.987 \\
\hline 3 & $85 \cdot 0$ & $90 \cdot 2$ & $85 \cdot 1$ & 0.944 \\
\hline 4 & $88 \cdot 6$ & 96.0 & $92 \cdot 4$ & 0.963 \\
\hline 5 & $91 \cdot 1$ & 96.9 & $89 \cdot 8$ & 0.927 \\
\hline 6 & 96.0 & $99 \cdot 0$ & 98.9 & 0.999 \\
\hline 7 & $89 \cdot 8$ & $91 \cdot 8$ & $91 \cdot 2$ & 0.994 \\
\hline 8 & $89 \cdot 9$ & $92 \cdot 8$ & $89 \cdot 5$ & 0.965 \\
\hline 9 & $87 \cdot 1$ & $90 \cdot 3$ & 86.6 & 0.959 \\
\hline 10 & $83 \cdot 7$ & $91 \cdot 9$ & $89 \cdot 3$ & 0.972 \\
\hline 11 & $84 \cdot 1$ & $85 \cdot 0$ & $86 \cdot 0$ & 1.012 \\
\hline 12 & $84 \cdot 5$ & $87 \cdot 9$ & $87 \cdot 0$ & 0.990 \\
\hline 13 & $74 \cdot 8$ & $77 \cdot 0$ & $76 \cdot 1$ & 0.988 \\
\hline 14 & $81 \cdot 2$ & 83.8 & $84 \cdot 1$ & 1.004 \\
\hline 15 & $75 \cdot 4$ & $81 \cdot 1$ & $78 \cdot 2$ & 0.964 \\
\hline 16 & $83 \cdot 7$ & $87 \cdot 6$ & $83 \cdot 8$ & 0.957 \\
\hline 17 & $104 \cdot 8$ & $104 \cdot 1$ & $102 \cdot 7$ & 0.981 \\
\hline 18 & $93 \cdot 1$ & $98 \cdot 9$ & $100 \cdot 1$ & $1 \cdot 012$ \\
\hline
\end{tabular}


bearing layer undoubtedly occurred. Further, some of the bonds produced by mechanisms described by Coutinho and Hughes and Ash may have been broken during the recovery stage. The increase in strength due to moisture loss is commonly observed. However, until the complex interaction between creep and shrinkage is fully understood, it will not be possible to account completely for the difference between creep under saturated or nearly saturated conditions and creep with simultaneous shrinkage.

\section{Reply by the authors}

We thank Dr Tam for his interesting discussion concerning the effects of sustained loading upon the strength of plain concrete. Dr Tam concludes that his results show that concrete specimens subjected to continuous water curing during the period of sustained loading will give a slight decrease $(2 \%)$ in short-term strength as opposed to an increase as observed by ourselves, and by Hughes and Ash and Coutinho (references 30 and 31 of our paper) for other environments. We, in general, disagree with this conclusion for the following reasons.

(1) In the curing procedure adopted by Dr Tam, there were slight differences between control cylinders and specimens subjected to sustained loading. Whereas control cylinders were kept in the fogroom throughout their curing history, others were continuously cured in water between 28 and 182 days. The additional pore pressure of specimens maintained in water will reduce strength.

(2) Tests recently conducted by us on 28 day concretes subjected to (i) air curing, (ii) 1 day in water +27 days in air, (iii) 7 days in water +21 days in air and (iv) 28 days in water showed that, for $12 \mathrm{~h}$ sustained loads at $70 \%$ maximum stress, the effect of sustained loads is unaffected by curing, and showed an increase in strength for all four curing conditions (Table II).

(3) The sustained stress level, $25 \%$ of the 28 day strength, employed by Dr Tam is considered to be too low to yield the beneficial effects associated with sustained loading. Tests recently performed by $\mathrm{Mr}$ J. G. L. Munday, a research student at the University of Dundee, indicate that there is little effect due to sustained loading at such low stress levels and that the optimum value lies in the range 60 to $80 \%$ maximum stress.
A possibly significant factor which may also have contributed to the lower strength values of Dr Tam's creep specimens is the loading history employed; in contrast to our tests, a recovery period was introduced. Although the period of recovery of 63 days probably eliminated some of the beneficial effects upon shortterm strength, we are of the opinion that such differences in loading procedure cannot account for the adverse effect observed by Dr Tam. This opinion is based on the results of recent studies on the autogenous healing of mortars ${ }^{(4)}$ and concretes which have shown that water-cured concrete is capable of healing itself in the presence of water to produce, at times, a material stronger than corresponding control cylinders, even for the severe case of specimens loaded to maximum stress.

TABLE II: Effect of sustained loading upon strength of concrete cured in different environments.

\begin{tabular}{l|c|c|c}
\hline \multirow{2}{*}{$\begin{array}{c}\text { Curing } \\
\text { conditions }\end{array}$} & \multicolumn{2}{|c|}{$\begin{array}{c}\text { Strength }\left(\mathrm{N} / \mathrm{mm}^{2}\right) \\
\text { Control } \\
\text { specimen }\end{array}$} & $\begin{array}{c}\text { Sustained } \\
\text { load } \\
\text { specimen } \\
\text { increase } \\
\text { due to } \\
\text { sustained } \\
\text { load }\end{array}$ \\
\hline $\begin{array}{l}28 \text { days in air } \\
1 \text { day in water }+\end{array}$ & 23.1 & 23.7 & 2.6 \\
$\begin{array}{l}27 \text { days in air } \\
7 \text { days in water }+\end{array}$ & 36.0 & 36.9 & 2.8 \\
21 days in air & 32.0 & $33.8^{*}$ & 2.5 \\
28 days in water & 28.6 & 5.6 \\
\hline
\end{tabular}

* The specimens were exposed to the laboratory atmosphere during the 12 hour period of sustained loading and would thus have also increased in strength due to drying effects.

\section{REFERENCES}

1. TAM, C. T. The effect of a lignin-based admixture on properties of concrete. Thesis submitted to the University of Calgary for the degree of PhD. 1972. pp. 192.

2. BAZANT, E. P. Thermodynamic theory of concrete deformation at variable temperature and humidity. Berkeley, Division of Structural Engineering and Structural Mechanics, University of California, August 1969. pp. 100. Report No. SESM 69-11.
3. MILLS, R. H. Collapse of structure and creep in concrete. Structure, Solid Mechanics and Engineering Design: The Proceedings of the Southampton 1969 Civil Engineering Materials Conferences. Editor: M. TE'ENI. London, WileyInterscience, 1971. Part 1. pp. 751-768.

4. DhiR, R. K., SAnGha, c. M. and munday, J. G. L. Strength and deformation properties of autogenously healed mortars. Journal of the American Concrete Institute. Proceedings Vol. 70, No. 3. March 1973. pp. 231-236. 